\title{
Atwater, Face, Green, and Greer to Chair 1997 MRS Fall Meeting
}

The Fall 1997 Materials Research Society Meeting in Boston, December 1-5, will be chaired by Harry A. Atwater, Dean W. Face, Peter F. Green, and A. Lindsay Greer. Comprising 41 symposia, the scope of the program reflects an increased emphasis on areas such as theory and modeling and biomaterials. New symposia in areas which MRS has previously not hosted are planned. Furthermore, the scope of some traditional symposia has been modified to reflect emerging trends. Also at this meeting, events are planned to recognize the 50th anniversary of the invention of the transistor. Overall, this program has the added dimension of providing an environment to facilitate new and exciting ideas and, moreover, attract new participants to the field.

Four stand-alone symposia in the area of theory and modeling are planned. These range from a reasonably focused symposium on the use of tight binding theoretical methods to a general symposium on modeling materials processes at different length scales using a variety of theoretical methodologies. Another symposium attempts to address the issues of modeling not just the processing of semiconductor materials but also their performance.

New symposia will be introduced to reflect emerging trends. For example, this is an appropriate time for MRS to host a symposium which addresses scientific and theoretical issues of thermal spray processing of materials. The scope of topics in the area of complex oxides has been expanded to include a new symposium on magnetic oxides. Topics in the area of biomaterials have also been expanded appreciably to include new areas which range from materials-science-related issues in living organisms to the use of organic polymers in orthopedics.

While some symposia which MRS has hosted in previous years are planned, the scope of others have been modified. For example, the symposium in the area of complex fluids which is typically hosted in the Fall of each year has been expanded to include biological molecules. A new symposium in the area of phase transformations and systems driven far from equilibrium should include contributions not only from the fields of ion beam analysis and ion implantation but others interested in the general topic of phase transformations.

Harry A. Atwater is Associate Professor of Applied Physics at the California Institute of Technology where he has been since joining the Caltech faculty as an Assistant Professor in 1988. He was an IBM postdoctoral fellow in applied physics at Harvard University from 1987 to 1988 . His research interests lie at the intersection of thin-film materials science, surface science, and semiconductor technology. Atwater's research program is focused on the synthesis and characterization of new thin-film electronic materials and development of new analytic and processing methods for electronic materials. He received his SB (1982), SM (1983), and $\mathrm{PhD}$ (1988) degrees in electrical engineering from the Massachusetts Institute of Technology. An NSF Presidential Young Investigator Award went to Atwater in 1989 , and he is a member of the Böhmische Physical Society. For 15 years, Atwater has been an active contributor to Fall and Spring MRS Meetings. He is chair of the Graduate Student Awards Subcommittee.

Dean W. Face is a Research Associate at DuPont in the Superconductivity business. His research interests include high-temperature superconducting materials, epitaxial oxide thin films, microwave devices, and SQUIDs. He is a Principal Editor for the Journal of Materials Research (JMR) and serves on the MRS publications committee. He has been an organizer for the MRS sym- posium on high-temperature superconductors (Spring 1994). Face also serves on the board of the Applied Superconductivity Conference and has served on the program committee. Prior to joining DuPont, he was a postdoctoral fellow at MIT. Face earned his BS degree in Electrical Engineering from the California Institute of Technology and his PhD degree in Applied Physics from Yale University in 1987.

Peter F. Green is currently an associate professor in the Department of Chemical Engineering at the University of Texas at Austin. Prior to his appointment at the University of Texas, he spent 11 years at Sandia National Laboratories, the last five of which he served as Manager of the Glass and Electronic Ceramics Research Department. He received his PhD degree in Materials Science and Engineering from Cornell University in 1985. In 1981, he received his $B A$ and MA degrees in Physics from Hunter College. His current research interests include dynamics, phase equilibria, and wetting transitions in polymers and dynamic processes in inorganic glasses. He is a Fellow of the American Physical Society.

A. Lindsay Greer is Reader in Microstructural Kinetics at the University of Cambridge, Department of Materials Science and Metallurgy, from where he received a BA degree in 1976 and a $\mathrm{PhD}$ degree in 1979. He has been Assistant Professor of Applied Physics in the Division of Applied Sciences at Harvard University from 1981 to 1984 . His research interests include metallic multilayers, atomic transport in thin films, rapid solidification, and amorphous and nanocrystalline metallic materials. In 1990 Greer has obtained the W.H. Zacharaisen award of the Journal of Non-Crystalline Solids. He has been a coorganizer of four MRS symposia and has served as a Principal Editor of JMR. MाRTS

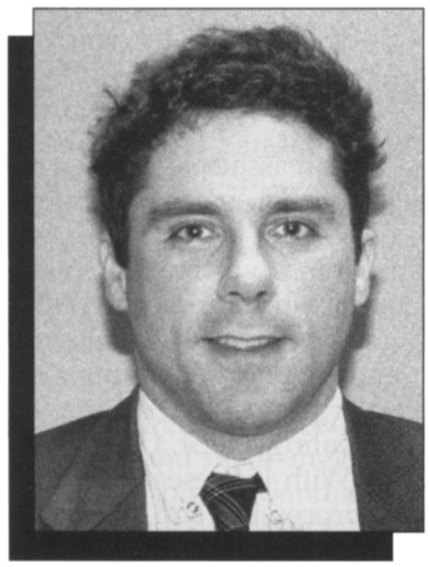

Harry A. Atwater

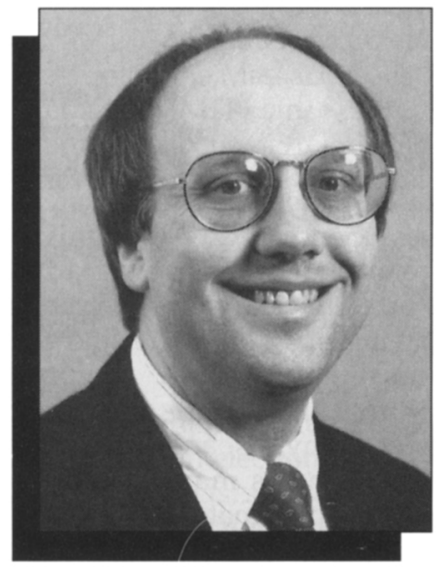

Dean W. Face

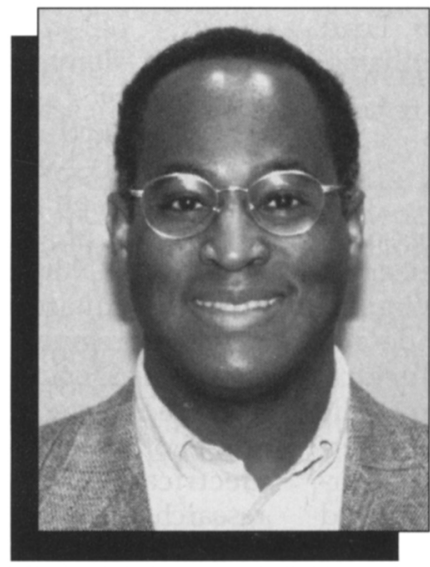

Peter F. Green

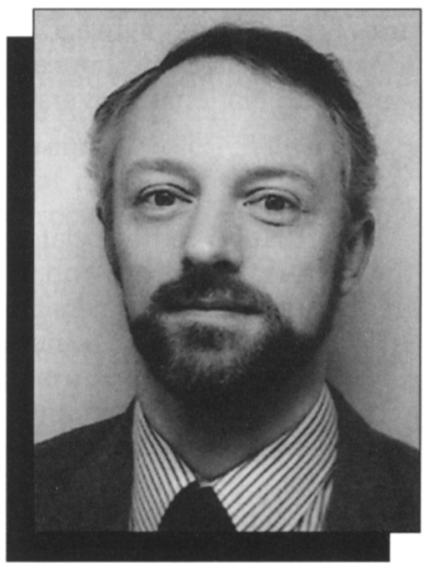

A. Lindsay Greer 